\title{
Idaho Rangeland Resource Commission: Commitment to Rangeland Education
}

\section{By Gretchen Hyde and Kelly Crane}

I daho is proud to co-host the 2012 SRM Annual Meeting. Rangelands are integral to the customs, culture, and economy of Idaho; nearly half of Idaho is rangeland. Eighty percent of the rangelands in Idaho are public lands administered by federal and state agencies. Consequently, public perceptions and associated public land policies have a profound influence on the use and management of Idaho rangelands. The Idaho Rangeland Resource Commission (IRRC) is uniquely charged with educating the public on the "responsible management of Idaho's rangelands."

In 1994, the Idaho legislature created the IRRC in response to the enthusiastic support of both livestock producers and rangeland managers throughout Idaho. The expressed objectives of this commission are to encourage sustainable rangeland management practices and to provide objective, proactive, educational programs about rangeland management to the citizens of Idaho. The IRRC is governed by a board of directors whose members are appointed by the Governor for a maximum of two consecutive, 5-year terms. ${ }^{1}$

The original IRRC board of directors consulted with representatives of Idaho's livestock industry to devise a funding mechanism. In 1997, funding for the IRRC was established through legislation that provided for a refundable assessment on public land animal unit months (\$0.10/animal unit month) and private category five dry grazing acres (\$0.02/ acre). ${ }^{2}$ As of 2011 , this rate continues, which provides approximately $\$ 190,000$ annual revenue to the IRRC. Since the establishment of the IRRC and the voluntary funding formula, less than $3 \%$ of the total revenue has been refunded to requesting landowners. Even through challenging economic conditions, Idaho ranchers continue their overwhelming support for the IRRC through voluntary contributions.

The IRRC continues to focus on the long-term educational objective of developing an informed public that supports responsible management of Idaho's rangelands. Specific goals associated with our educational objective are as follows: to increase public understanding that Idaho's

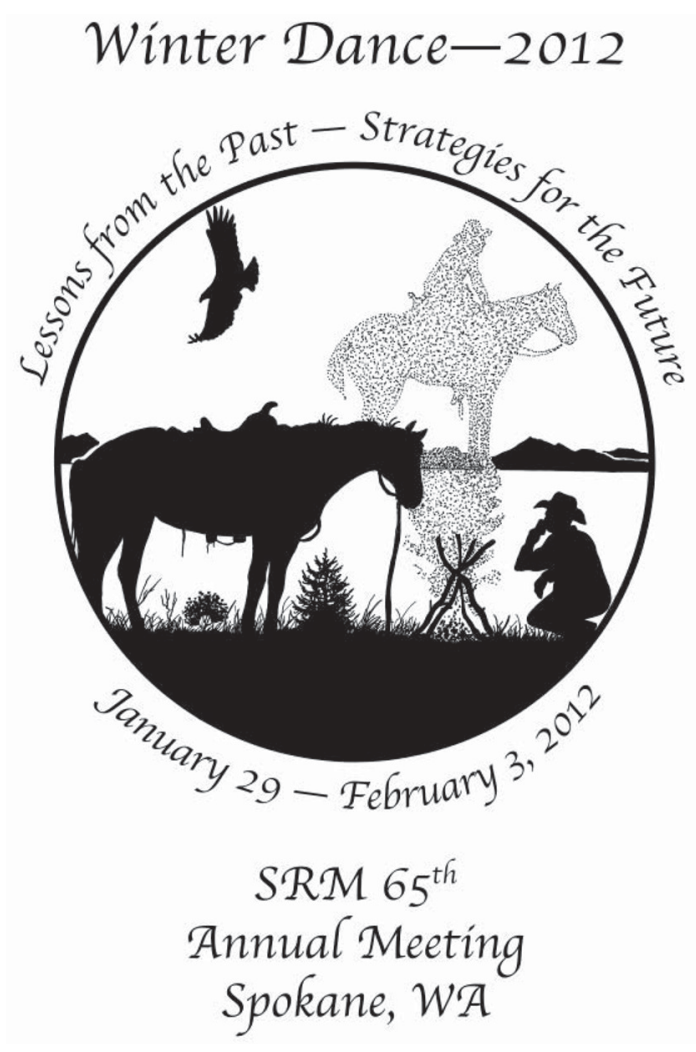

rangelands are a renewable source of important consumer products and environmental values; to provide and disseminate factual information about the economic and ecological aspects of rangeland management practices; to promote public support for sustainable livestock grazing on Idaho's rangelands; to help promote responsible rangeland stewardship; and to advocate balanced multiple use of the rangeland resources. The IRRC is constantly vigilant to remain focused on educational objectives and objectivity.

Thanks to the efforts of IRRC and their partnership with the University of Idaho (UI), Idahoans know rangelands. Our citizens enjoy widespread IRRC media campaigns that highlight the values, benefits, and importance of Idaho rangelands. Innumerable people in Idaho have 

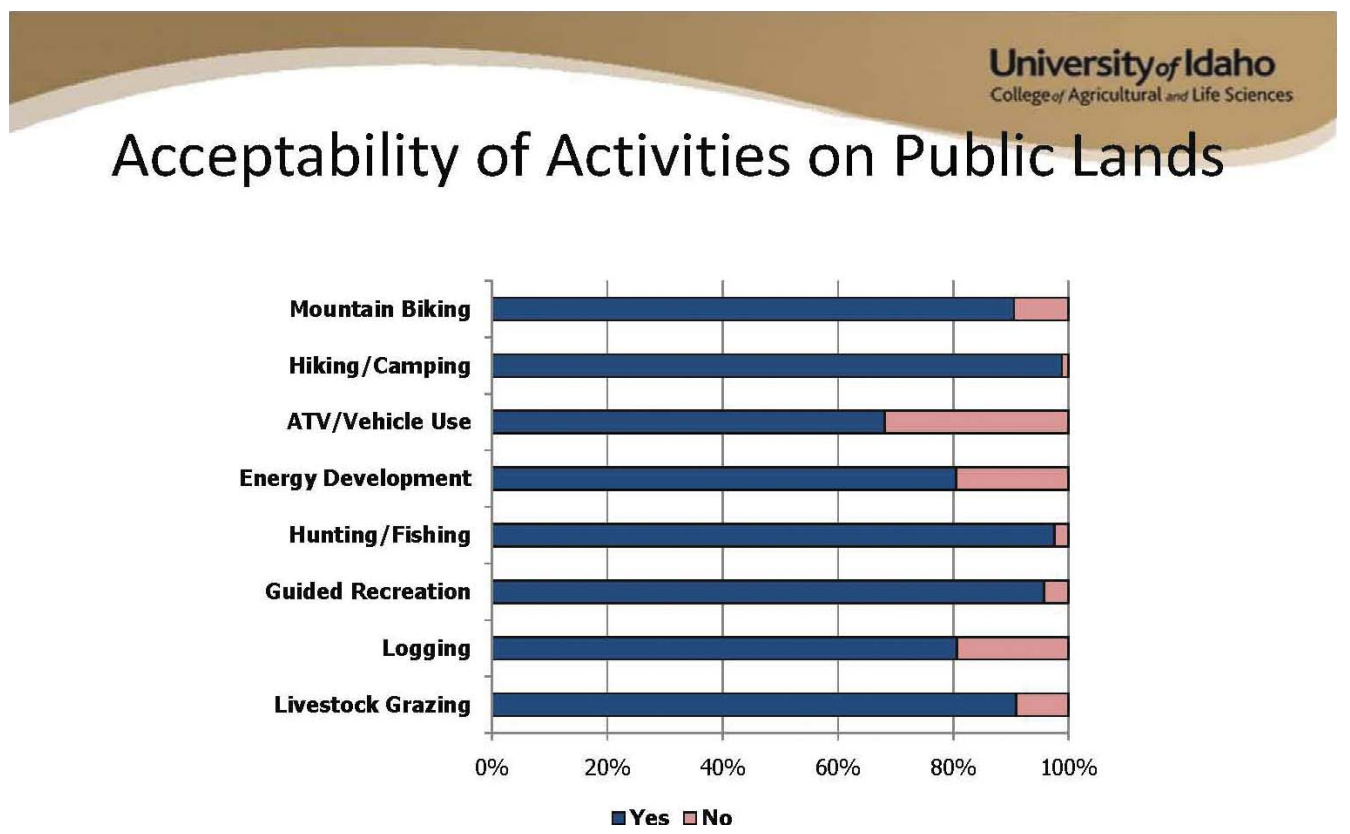

Figure 1. Most Idahoans consider livestock grazing an acceptable use of public rangelands. ${ }^{3}$ Reprinted with permission.

gained a more in-depth understanding of rangelands through participation in IRRC educational programs such as:

- Rangeland curriculum and teaching materials for grades $\mathrm{K}-12$;

- Rangeland ecology continuing-education workshops for educators;

- Idaho and Western National Rangeland Assessment events for Future Farmers of America (FFA) participants;

- Idaho Range Plants and Rangeland History publications;

- Ranch stories on interactive website, LifeOntheRange. org; and

- Care/Share outreach program and materials for recreational users.

The long-term collaboration between IRRC and UI advances the goals of both organizations. In Idaho, rangeland education is supported by IRRC-developed curriculum from elementary to high school science classes and FFA career development events. The return on investment of this nontraditional outreach program for UI is increasing enrollment in rangeland courses in Moscow, Idaho, and a growing constituency of supporters throughout the state. At a time when many universities are shifting resources away from rangeland programs, UI has initiated the development of a Rangeland Center to meet the research, education, and outreach needs of Idaho students and stakeholders.

The IRRC undoubtedly has had a positive impact on public perceptions regarding rangeland uses in Idaho. A statewide poll, conducted in 2010, indicated that an overwhelming majority (89\%) of Idahoans considers livestock grazing an acceptable use of public rangelands (Fig. 1). ${ }^{3}$ In 1997, a similar survey conducted by Dan Jones and Associates indicated that $80 \%$ of the public approved of livestock grazing on public lands. The 2010 survey also suggested that respondents consider ranchers a reliable source of information about rangelands and that ranches and farms are compatible with the conservation of endangered species. ${ }^{i}$

The IRRC utilizes the lessons of the past to build programs and materials to educate the citizens of Idaho to support responsible management of Idaho's rangelands. These strategies and others will be showcased during the 2012 Annual SRM Meeting in Spokane, Washington.

\section{References}

1. Idaho Statute, Title 58, Chapter 14 (58-1403). 1994. Idaho Rangelands Resource Commission: Rangeland Resources Commission created-members. Available at: http://www. legislature.idaho.gov/idstat/Title58/T58CH14SECT58-1403. htm. Accessed 20 June 2011.

2. Idaho Statute, Title 58, Chapter 14 (58-1414A). 1997. Idaho Rangelands Resource Commission: imposition of fees. Available at: http://www.legislature.idaho.gov/idstat/Title58/ T58CH14SECT58-1414A.htm. Accessed 10 June 2011.

3. Kane, S. L., B. E. Foltz, and J. D. Wulfhorst. 2010. Idaho Rangeland Resource Commission and Idaho Preferred Statewide Survey: SSRU Technical Report 10-08-22. Moscow, ID, USA: University of Idaho. 85 p.

Authors are Executive Director, Idaho Rangeland Resource Commission, PO Box 126, Emmett, ID 83617, USA, www. idahorange.org, ghyde@idahorange.org (Hyde); and Range Extension Specialist, University of Idaho, Twin Falls Research and Extension Center, PO Box 1827, Twin Falls, ID 83303, USA (Crane).

'To view a summary of the results of the 2010 poll, visit the IRRC website available at www.idahorange.org. 